\title{
Gestão social dos territórios da cidadania: 0 zoneamento ecológico-econômico como instrumento de gestão do território noroeste de Minas Gerais
}

\section{Social management of the territories of citizenship: ecological and economic zoning as a management tool for the northwest territory of Minas Gerais}

\author{
José Roberto Pereira ${ }^{1}$ \\ Patrícia Aparecida Ferreira ${ }^{2}$ \\ Ana Alice Vilas Boas ${ }^{3}$ \\ Elias Rodrigues de Oliveira ${ }^{4}$ \\ Raquel Finamor Cardoso ${ }^{5}$
}

\begin{abstract}
Resumo
O enfoque territorial tornou-se referência para os estudos sobre desenvolvimento e gestão social, pois rompe com o anacronismo da ideia de que o desenvolvimento se restringe ao crescimento econômico, uma vez que incorporou outras dimensões, tais como as sociais, políticas, institucionais e ambientais. Nesse sentido, o objetivo deste artigo é mostrar que os resultados do Zoneamento Ecológico-Econômico (ZEE) constitui um instrumento de gestão social para o território da cidadania do noroeste de Minas Gerais. O ZEE é expresso pelo Índice Ecológico-Econômico (IEE), formado pela integração de dois índices, o da potencialidade social dos municípios e o da vulnerabilidade natural. Para este artigo, são apresentados os resultados da potencialidade social dos municípios em forma de tabelas, quadros e mapas. O Índice de Potencialidade Social (IPS) é estruturado por 36 indicadores socioeconômicos e institucionais e por quatro componentes: produtivo, natural, humano e institucional. Os resultados do ZEE-MG constituem, efetivamente, um instrumento de gestão social dos territórios da cidadania, pois representam transparência e responsabilização pública e um pacto social para o desenvolvimento por meio de indicadores socioeconômicos, que serve ao terceiro setor, ao setor público e ao mercado para tomada de decisões públicas integradas no âmbito municipal, regional, estadual e federal.
\end{abstract}

Palavras-chave: Território. Cidadania. Zoneamento. Gestão social.

Artigo submetido em 16 de março de 2011 e aceito para publicação em 04 de agosto de 2011.

1

Doutor em Sociologia pela Universidade de Brasília (UnB); Professor Associado da Universidade Federal de Lavras (UFLA); Bolsista CNPq e Pesquisador Mineiro pela FAPEMIG. Endereço: Universidade Federal de Lavras (UFLA), Diretoria de Contratos e Convênios - DICON - Prédio da Reitoria, CEP 37200-000, Lavras - MG, Brasil. E-mail: jrobpereira25@yahoo.com.br

2 Graduada e mestre em Administração pela UFLA. Endereço: Departamento de Administração e Economia (DAE), CEP 37200-000, Lavras - MG, Brasil. E-mail: pattty82@yahoo.com.br

3 Graduada em Administração Rural (UFLA); Bacharel Administração de Empresas (FIS); Mestre em Administração (UFLA); Doutora em Administração (Universidade de Reading - Inglaterra); PhD em Administração (Universidade de Reading - UK). Endereço: Via San Paolino, n. 35. Condomínio Província di Lucca. Parque Belvedere, CEP 37200-000, Lavras - MG, Brasil. E-mail: ana.alice@dae.ufla.br

4 Engenheiro Agrônomo; Mestre e Doutor em Administração (UFLA). Endereço: Universidade Federal de Lavras - UFLA, Departamento de Administração e Economia (DAE), CEP 37200-000, Lavras - MG, Brasil. E-mail: eliasdae@dae.com.br

5 Graduada em Administração pelo Centro de Ensino Superior em Gestão, Tecnologia e Educação em Santa Rita do Sapucaí-MG; Mestranda em Administração (UFLA). Endereço: Santos Dumont, n.134, Palmeiras, CEP 37220-000, Bom Sucesso - MG, Brasil. Email: raquelfinamor@yahoo.com.br 


\begin{abstract}
The territorial approach has become a reference for studies on development and social management, as it breaks with the anachronistic idea that development is restricted to economic growth, since it incorporated other dimensions such as the social, political, institutional and environmental. Thus, the aim of this paper is to show that the results of Ecological-Economic Zoning (EEZ) is an instrument of social management for the northwest territory of Minas Gerais state, Brazil. The EEZ is expressed by the Ecological-Economic Index (EEI), formed by integrating two indices: the social potential of cities and natural vulnerability. For this article, we present the results of the social potential of the cities in the form of tables, charts and maps. The Potential Social Index (PSI) is formed by 36 institutional and socioeconomic indicators grouped into four components: production, natural, human and institutional resources. The results of EEZ-MG do indeed show that it is an instrument of social management of citizenship because they represent public accountability and transparency, and the construction of a social pact for development through socioeconomic indicators. The EEZ-MG is a tool for the third sector, public sector and the market to integrate public decision-making at the municipal, regional, state and federal levels.
\end{abstract}

Keywords: Territory. Citizenship. Zoning. Social management.

\title{
Introdução
}

Durante muito tempo acreditou-se na teoria de que o desenvolvimento era consequência direta do crescimento econômico. No entanto, com o passar dos anos, novas abordagens foram construídas, sendo o enfoque territorial uma das importantes unidades de análise conceitual e de referência para os estudos sobre desenvolvimento. Esse enfoque rompeu com a ideia anacrônica de que o desenvolvimento se restringe ao crescimento econômico, uma vez que incorporou outras dimensões, tais como as sociais, políticas, institucionais e ambientais. Além disso, este novo paradigma de desenvolvimento não descartou a dimensão econômica, que entrou em consonância com outras dimensões que envolvem a discussão contemporânea sobre desenvolvimento.

Para conhecer as especificidades das multidimensões presentes nos territórios (municípios, regiões, estados ou até mesmo nações), torna-se necessário o uso de instrumentos que forneçam informações para o planejamento e a gestão de políticas de desenvolvimento. Dentre os possíveis instrumentos, destaca-se o Zoneamento Ecológico-Econômico (ZEE), cujo objetivo, segundo Steinberger e Romero (2000), consiste na busca de indicadores que expressam a associação apropriada entre as diversas variáveis que compõem as dimensões que orientam o desenvolvimento territorial.

Por ter esse caráter indicativo, o ZEE oferece indicadores e índices que condensam informações, que podem ser utilizadas como elementos norteadores para monitorar, acompanhar e avaliar o planejamento, ou seja, pode ser utilizado como instrumento de gestão territorial. Com o ZEE é possível orientar a formulação de políticas públicas setoriais com maior precisão e consistência, orientar decisões no âmbito da gestão do território, orientar organismos governamentais e não governamentais na intervenção social no âmbito municipal, orientar contratos entre iniciativas privadas e governos, bem como servir de referência para ações judiciais de caráter público. Portanto, serve de base para a gestão social do território, tendo em vista que o Programa Territórios da Cidadania, como política pública federal, adotou um modelo de gestão social que se pauta nos princípios da participação, descentralização, democracia e transparência.

Neste contexto, o objetivo deste artigo é mostrar que os resultados do Zoneamento Ecológico-Econômico constitui um instrumento de gestão social para o território da cidadania do noroeste de Minas Gerais. A partir das informações do ZEE, o Colegiado Territorial, que tem a responsabilidade técnica de elaborar o plano de desenvolvimento do território, poderá tomar como base os resultados do zoneamento disponíveis na internet 
(www.zee.mg.gov.br) para elaboração do referido plano e colocar em prática os princípios norteadores da gestão social mencionados acima. Sabemos que os Conselhos de Desenvolvimento dos Territórios (CODETER) possuem informações socioeconômicas dos Territórios da Cidadania agrupadas no Atlas dos Territórios Rurais, publicado em 2004 pelo Ministério do Desenvolvimento Agrário (MDA), que reuniu amplo conjunto de variáveis sociais, demográficas, econômicas e espaciais com o propósito de servir de base para o planejamento, os diagnósticos e processos de priorização das ações de desenvolvimento rural (FAVARETO, 2010). Esse Atlas serviu de base para a criação do Sistema de Informação Territorial disponível em um sistema informatizado na WEB (http://sit.mda.gov.br/), onde se pode ter acesso público às referidas informações. No entanto, os dois tipos de acesso apresentam conjuntos de informações diversas, mas complementares. É nesse sentido que acreditamos que o ZEE-MG pode contribuir, significativamente, para "empoderar" os atores sociais que fazem parte do CODETER do noroeste de Minas Gerais. Portanto, gestores de políticas públicas, organizações sociais, prefeitos municipais e governos federal e estadual podem identificar a potencialidade social de cada município e criar mecanismos de controle, de transparência pública e de accountability, tornando possível a interface entre gestão social e gestão pública, estabelecendo metas e objetivos de curto, médio e longo prazo para o desenvolvimento do território.

A Potencialidade Social de que trata o ZEE representa a condição real, especialmente do "capital social", de efetivar o que Sen (2000) denomina de liberdade substantiva, pré-requisito para o Desenvolvimento Sustentável. Assim, partiu-se do pressuposto de que todo município tem uma Potencialidade Social que determina seu ponto de partida para o Desenvolvimento Sustentável, ou seja, todo município possui um conjunto de condições naturais, produtivas, humanas e institucionais que constitui o "Ponto de Partida de Potencialidade Social". Compreende-se, então, como potencialidade social o conjunto de condições atuais, medido pelas dimensões produtiva, natural, humana e institucional, que determina o ponto de partida de um município ou de uma região para alcançar o desenvolvimento sustentável. As categorias de potencialidade social representam o ponto de partida para o desenvolvimento sustentável dos municípios, das regiões e do estado de Minas Gerais. Assim, identificar as potencialidades sociais e as vulnerabilidades naturais do território da cidadania do noroeste de Minas Gerais constitui a base para o desenvolvimento da gestão social do referido território. Neste sentido, dentre outros conceitos presentes na literatura científica, compreende-se gestão social, segundo Tenório (2008, p.158, grifo do autor), “como processo gerencial dialógico em que a autoridade decisória é compartilhada entre os participantes da ação (ação que possa ocorrer em qualquer tipo de sistema social - público, privado ou de organizações não-governamentais). O adjetivo social qualificando o substantivo gestão será entendido como o espaço privilegiado de relações sociais no qual todos têm o direito à fala, sem nenhum tipo de coação".

Em termos metodológicos, o ZEE-MG se fundamenta na sistematização de dados secundários. A base de dados utilizada é municipal e está espacializada e representada em cartas, bem como disponibilizadas em um banco de dados. Não foram feitos levantamentos primários de informações. Todos os dados e informações foram obtidos em fontes oficiais de instituições ou órgãos de reconhecida competência, seja no âmbito federal, estadual ou municipal.

Para categorizar os municípios quanto à sua potencialidade social, tomou-se como referência a comparação entre os dados do município e os dados dos 853 municípios do estado de Minas Gerais. Desta forma pode-se situá-lo dentro de um continum que varia entre um número mínimo e um número máximo de cada indicador utilizado, que corresponde, por sua vez, ao mínimo de um ponto e ao máximo de cinco pontos representados, simbolicamente, pelas letras do alfabeto “A, B, C, D, E". Desta forma, cada ponto e cada letra correspondem a uma categoria específica, representativa da potencialidade social real de cada município. As cinco categorias utilizadas para classificação dos municípios são apresentadas no Quadro 1. Os pontos que correspondem a cada categoria foram atribuídos de acordo com o resultado da aplicação do método de análise multivariada por componentes principais, estabelecendo-se cinco intervalos "percentílicos" para cada indicador de acordo com a variabilidade dos dados. 
Quadro 1

Categorias para classificação dos municípios quanto as pontecialidades sociais

\begin{tabular}{|l|l|}
\hline \multicolumn{1}{|c|}{ CATEGORIA/PONTOS } & \multicolumn{1}{c|}{ TIPO DE POTENCIALIDADE SOCIAL } \\
\hline A = 5 & Ponto de Partida em Condições Muito Favoráveis \\
\hline B = 4 & Ponto de Partida em Condições Favoráveis \\
\hline C = 3 & Ponto de Partida em Condições Pouco Favoráveis \\
\hline D = 2 & Ponto de Partida em Condições Precárias \\
\hline E = 1 & Ponto de Partida em Condições Muito Precárias \\
\hline
\end{tabular}

Fonte: Pereira (2008a).

Como resultado da pontuação derivada dos cinco intervalos "percentílicos", foram plotadas cartas para cada indicador, para cada fator condicionante, e para cada componente da potencialidade social, utilizando-se o programa "ArcGIS" (Mapping and Spatial Analysis for Understanding Our World). Assim, a cada categoria corresponde um número e uma cor, apresentada nas cartas, que diferencia um município do outro. As cores utilizadas nas cartas são equivalentes às categorias e aos pontos utilizados para categorizar os municípios, como podem ser observadas no Quadro 2.

Quadro 2

Equivalência entre categorias, pontos e cores

\begin{tabular}{|l|l|l|}
\hline \multicolumn{1}{|c|}{ CATEGORIA } & \multicolumn{1}{|c|}{ PONTOS } & \multicolumn{1}{c|}{ CORES } \\
\hline A & 5 & Azul \\
\hline B & 4 & Azul Claro \\
\hline C & 3 & Verde \\
\hline D & 2 & Amarelo \\
\hline E & 1 & Vermelho \\
\hline
\end{tabular}

Fonte: Pereira (2008a).

A categorização dos municípios tem como pressuposto básico o fato de que os municípios partem de pontos diferenciados de condições produtivas, naturais, humanas e institucionais e, portanto, devem ser tratados pela ação pública e social de forma diferenciada. Tratar de forma diferenciada significa, no contexto do desenvolvimento sustentável e da gestão social, tratar equitativamente a realidade de cada município na sua especificidade e nas suas demandas. Assim, com base nessa categorização, a gestão social do território da 
cidadania, a qual inclui todos os atores envolvidos na ação pública, poderá tomar decisões estratégicas, definir metas, recursos, prazos e elaborar planejamento para a região de forma mais adequada a cada realidade. Além disso, poder-se-á desenhar cenários específicos como estratégia de intervenção social, tomando-se também, como base, os resultados dos diagnósticos e planos disponíveis no Sistema de Informações Territoriais do MDA.

Para estabelecer as cinco categorias de potencialidade social, partiu-se dos componentes produtivo, natural, humano e institucional. Para cada componente estabeleceu-se um conjunto de fatores condicionantes e, respectivamente, para cada fator condicionante estabeleceu-se um conjunto de indicadores. Por sua vez, cada indicador foi constituído por um conjunto de variáveis obtidas por meio de dados censitários, de fontes oficiais, os mais atualizados possíveis. Fator Condicionante corresponde a um conjunto de Indicadores, pontuados de acordo com critérios estatísticos (análise multivariada por componentes principais), e possui a condição de representar uma mudança para melhor ou para pior de uma determinada realidade. Indicador é a medida de um dado ou de uma informação quantitativa que revela a situação do fator condicionante respectivo, formado por um conjunto de variáveis. Variáveis são dados ou informações quantitativas que podem ter ou assumir diferentes valores, diferentes aspectos, segundo os casos particulares ou segundo as circunstâncias. Portanto, componentes, fatores condicionantes, indicadores e variáveis formam a estrutura metodológica de diagnosticar a realidade dos municípios, em termos de potencialidade social.

Este artigo está estruturado em cinco seções, contando com esta introdução. Na seção 2 são apresentados o contexto histórico de institucionalização do ZEE, alguns conceitos a respeito de território, destacando-se a aplicabilidade do ZEE como instrumento de gestão. Na seção 3 são apresentados os resultados do ZEE para os 853 municípios mineiros e suas regiões, bem como a estrutura de interpretação dos respectivos resultados. $\mathrm{Na}$ seção 4 são apresentados os resultados obtidos por meio do ZEE-MG para os 22 municípios que compõem a região noroeste, incluída como Território da Cidadania pelo governo federal. A seção 5 trata das considerações finais, onde são apresentadas algumas análises sintéticas que revelam o alcance desse trabalho.

\section{Zoneamento Ecológico-Econômico: um Instrumento de Gestão Social do Território}

A origem dos zoneamentos no Brasil está relacionada às necessidades advindas das análises a respeito de impactos ambientais na década de 1970, o que adquiriu força com a promulgação da Lei ${ }^{\circ}$ 6.938, em 1981, que estabelecia os objetivos e as normas da Política Nacional de Meio Ambiente (PNMA), fazendo referência ao zoneamento ambiental como instrumento de política. No entanto, apenas em 1986 é que o IBGE (Instituto Brasileiro de Geografia e Estatística) elaborou uma proposta de zoneamento ecológicoeconômico no Brasil, mas não foi implementada (BECKER e EGLER, 1997). Contudo, o zoneamento ecológico-econômico só foi institucionalizado como instrumento de ordenação territorial em 1990, com o Decreto $n^{\circ}$ 99.193/90 que criou o Programa de Zoneamento Ecológico-Econômico (PZEE) e o Decreto ${ }^{\circ}$ 99.540/1990, que criou a Comissão Coordenadora do Zoneamento Ecológico-Econômico do Território Nacional (CCZEE). As atribuições desta comissão era planejar, coordenar, acompanhar e avaliar a execução dos trabalhos de zoneamento ecológico-econômico no território nacional. Entretanto, somente a partir de 2000 é que o PZEE passou a integrar o planejamento federal como um dos instrumentos do Plano Plurianual 2000-2003 (PPA 2000-2003), recebendo recursos para sua execução. Mesmo assim, só foi possível alcançar uma metodologia padrão do Programa e estabelecer procedimentos operacionais de zoneamento, a partir da publicação do documento intitulado "Programa Zoneamento Ecológico-Econômico: diretrizes metodológicas para zoneamento ecológico-econômico do Brasil" (BRASIL, 2006).

De acordo com Steinberger e Romero (2000), o termo "zoneamento", embora esteja associado a algumas conhecidas experiências de planejamento, como o tradicional zoneamento urbano e o zoneamento agrícola 
ou agroecológico, a acepção de Zoneamento Ecológico-Econômico partiu da ideia, enunciada no II Plano Nacional de Desenvolvimento (1974), sobre a necessidade de conciliar o desenvolvimento econômico em alta velocidade com o mínimo de efeitos danosos sobre o meio ambiente. Nesse sentido, esses autores enumeram alguns períodos que colaboraram para um refinamento da concepção do ZEE enquanto instrumento de gestão:

- Ano de 1986 - o ZEE começou a ser oficialmente concebido pelo Instituto Brasileiro de Geografia e Estatística - IBGE, com o objetivo de realizar divisões e classificações do espaço, por meio do cruzamento de fatores ecológicos e socioeconômicos. Essa concepção considerava o ZEE como um instrumento de caráter governamental federal e não previa a sua participação ativa, nem de outras esferas de governo e nem da comunidade. Entretanto, ainda na segunda metade da década de 80, algumas ações contribuíram para que o ZEE começasse a se transformar em um instrumento mais democrático de planejamento, tais como a promulgação da nova Constituição e a pressão internacional sobre o Brasil no que se referia à destruição da floresta amazônica;

- Início da década de 90 - a atribuição de coordenar o ZEE passou a ser exercida pela Secretaria de Assuntos Estratégicos (SAE), que o definiu como instrumento de uma política de ordenação territorial lastreada no desenvolvimento sustentável. A ordenação do território foi entendida como sendo a expressão espacial das políticas econômica, social, cultural e ecológica. Além disso, o ZEE também foi definido como instrumento para racionalizar a ocupação dos espaços, subsidiar a elaboração de planos regionais e dotar o governo de bases técnicas para espacialização das políticas públicas visando à ordenação do território. Esclareceu-se ainda que o ZEE deveria ser conduzido como processo dinâmico e contínuo, exigindo detalhamentos de acordo com as prioridades nacionais, regionais e locais. Por fim, considerou-se que a sua execução dependeria de uma ação integrada e descentralizada do Governo Federal com participação efetiva dos Estados, tanto no planejamento como na implementação das intervenções em seus territórios. Entretanto, a despeito da descentralização prevista, o ZEE ainda era um instrumento de base estritamente governamental, pois as entidades da sociedade civil não tinham participação plena;

- Ano de 1994 - marcou uma nova mudança na concepção do ZEE, que foi inserido como um instrumento de gestão ambiental do Subprograma de Política de Recursos Naturais (SPRN) a ser implementado em regiões prioritárias selecionadas pelos Estados. Neste sentido estabeleceria "referenciais para a orientação da ocupação do território, com vistas à proteção da biodiversidade e ao uso sustentável dos recursos naturais";

- Ano de 1997 - com o intuito de dar mais operacionalidade ao ZEE, este passou a ser considerado como um instrumento técnico de gestão territorial (provê informação integrada em uma base geográfica e classifica o território segundo suas potencialidades e vulnerabilidades) e político (permite integrar políticas públicas e é instrumento de negociação entre esferas do governo, setor privado e a sociedade civil).

Em Minas Gerais, em 2003, no Plano Plurianual de Ação Governamental 2004-2007 (PPAG 2004-2007) o governo do estado, dentro do que ficou conhecido como "Choque de Gestão", propôs 31 "Projetos Estruturadores" (projetos prioritários), dentre os quais, o Projeto Estruturador $n^{\circ} 17$ (PE 17) - Gestão Ambiental no Século XXI. Dentre as diversas ações colocadas em curso por esse Projeto Estruturador 17 destaca-se a Ação P322, em que são estabelecidos os termos para a realização do ZEE-MG (MINAS GERAIS, 2005). Segundo Scolforo, Oliveira e Carvalho (2008, p. 1), os objetivos do ZEE-MG é "subsidiar o planejamento e orientação das políticas públicas e das ações em meio ambiente nas regiões, por meio de um macrodiagnóstico do estado, viabilizando a gestão territorial, estimulando a participação dos Conselhos Plurais, COPAM (Conselho de Política Ambiental), CERH (Conselho Estadual de Recursos Hídricos) e 
Comitês de Bacia, com vistas à sua gestão, segundo critérios de sustentabilidade econômica, social, ecológica e ambiental".

Segundo Veiga (2001), dentre os instrumentos de gestão territorial existentes, destaca-se o Zoneamento Ecológico-Econômico (ZEE) como uma das principais alavancas do desenvolvimento territorial, pois representa muito mais do que um estudo das condições físicas e socioeconômicas dos municípios, regiões, estados ou nações, sendo também uma forma de negociação e de ajuste entre as diversas visões sobre desenvolvimento.

A abordagem territorial também carece de meios de diagnóstico que forneçam informações sobre uma determinada realidade e que sejam fontes de referência para a formulação e implementação de estratégias ou de políticas públicas. Dentre essas formas de diagnóstico, Acselrad (2000), Oliveira (2004), Steinberger e Romero (2000) e Veiga (2001) destacam o Zoneamento Ecológico-Econômico como um instrumento de gestão do desenvolvimento, mais especificamente, vinculado a dimensão territorial.

Diante dessas colocações, Steinberger e Romero (2000) definem o ZEE não com um plano nem como uma política, visto que este representa um instrumento indicativo e dinâmico para tomada de decisões e formulação de políticas. O caráter indicativo do ZEE se expressa pela identificação da vulnerabilidade e da potencialidade de dadas porções do território. Enquanto o caráter dinâmico refere-se à necessidade de que o ZEE seja permanentemente revisto e atualizado. Dessa forma, o ZEE pode ser compreendido como um instrumento de gestão social e de gestão pública, uma vez que incorpora dados e informações com revisão periódica e adaptação à realidade ecológica e econômica de cada momento, implicando uma ação permanente de apoio a decisões quanto à política de desenvolvimento de um dado território.

Por essa razão o ZEE não utiliza uma metodologia preestabelecida, mas constrói-se a partir de um patamar metodológico, o qual pressupõe uma abordagem transdisciplinar que observe a dinâmica dos sistemas ambientais e das formações socioeconômicas e culturais por meio de hierarquias de escalas espaciais e temporais, estabelecendo sempre interações entre seus componentes (STEINBERGER e ROMERO, 2000).

Quanto à condução de um ZEE, Acselrad (2000) salienta a possibilidade de se deparar com dificuldades metodológicas na busca de indicadores que expressam a associação apropriada entre variáveis sociais e geofisiográficas, devido à complexidade encontrada nas dinâmicas socioterritoriais. Nesse sentido, esse autor destaca que os diferentes discursos sobre as metodologias do ZEE carregam ambiguidades internas, expressivas na duplicidade de caráter, ou seja, é ao mesmo tempo um instrumento técnico e político.

Para Oliveira (2004), uma metodologia adequada a ser utilizada na implementação de um ZEE requer um cuidado especial quanto ao produto a ser produzido e sua utilidade enquanto instrumento de suporte à decisão tanto em escala regional como também na escala municipal ou mesmo territorial. Nessa ótica, o núcleo central de implementação de um ZEE deve ser reflexivo e mais ancorado na sociologia complexa do território, cujo trabalho consiste em evidenciar o modelo de desenvolvimento a que o zoneamento se associa, identificando, assim, o conjunto de forças sociais que sustentam esse modelo.

Selecionada a metodologia que dialogue com a diversidade social em seus diferentes níveis de articulação e configuração, o próximo passo do ZEE, segundo Oliveira (2004), consiste em um processo de classificação do espaço geográfico em subunidades territoriais, que deverão ser agrupadas conformes os níveis de aptidão para determinados tipos de ocupação. A determinação das diferentes aptidões de cada trecho do espaço territorial analisado deve ser baseada em critérios científicos.

Quanto aos resultados do processo de um ZEE, observa-se que estes se materializam sob a forma de um conjunto de cartas-síntese e informações a elas associadas. Em cada uma dessas cartas estão contidas informações sobre a aptidão das subunidades do território para cada tipo de ocupação específica 
(OLIVEIRA, 2004). Para Acselrad (2000), as cartas como característica central de um ZEE devem ser vistas como "mapas falantes" por si mesmos, que se apresentam não como reflexos passivos do mundo dos objetos, mas como intérpretes do que alguns pretendem que seja "a verdade ecológica, social e econômica deste mundo". Explicitamente, as cartas do ZEE "ordenam e dão ordens". Seus enunciados são de caráter performático, pois a cartografia no ZEE contém uma dupla temporalidade - a da história demarcada espacialmente por meio de signos selecionados e a do futuro imaginado, representando as coisas como tensão na qual o lugar geográfico é, ao mesmo tempo, um horizonte.

Nesse sentido, o ZEE se insere, dentre as diferentes perspectivas analíticas, na que trata o território como categoria de análise de intervenção por meio de políticas públicas, como considera Bronzo (2007). A dimensão de território para essa autora, aliada à de comunidade, forma uma categoria analítica denominada por ela de "infraestrutura social". Assim, território é considerado por essa autora como uma "(...) perspectiva que dirige o olhar para as condições da infraestrutura urbana e de bens e serviços em diversos 'pedaços' da cidade e também considera a dimensão das relações sociais que configuram o tipo de organização social existente" (BRONZO, 2007, p. 98). Além disso, a noção de território articula-se à noção de redes governamentais, sociais, locais, de serviços que integram a infraestrutura social, analisa a autora: "Infraestrutura social entendida ao mesmo tempo como rede de serviços e como organização social, (...)" (BRONZO, 2007, p. 100). Considerando esses conceitos, Bronzo (2007, p. 94) destaca três questões centrais para o desenho de políticas de inclusão social, como é o caso dos territórios da cidadania, quais sejam: "centralidade do território para as políticas sociais, seja como elemento para o diagnóstico e a focalização, seja como objeto de intervenção; a noção de infraestrutura social; a atenção necessária às formas flexíveis de provisão dos serviços."

Por outro lado, observa-se um significado cada vez mais relevante ao enfoque territorial, que tem se apresentado como uma importante unidade de análise conceitual e de referência normativa entre os estudiosos do tema (SCHNEIDER, 2004). Essa adjetivação territorial do desenvolvimento é compreendida por Petter, Petter e Quadros (2007), como parte de uma ideia central de que o território é mais do que uma simples base física para as relações entre indivíduos e empresas, pois possui um tecido social, interelações complexas que vão além de seus atributos naturais. Nesse sentido, incorporam-se as colocações feitas por Gil (2004), de que o território é o fruto de processos de apropriação e domínio de um espaço, inscrito em um campo de forças, de relações de poder econômico, político e cultural. O Ministério do Desenvolvimento Agrário (2003, p. 20) também corrobora com essa definição e concebe o território como:

Um espaço físico, geograficamente definido, geralmente contínuo, compreendendo cidades e campos, caracterizados por critérios multidimensionais, tais como o ambiente, a economia, a sociedade, a cultura, a política e as instituições, e uma população, com grupos sociais relativamente distintos, que se relacionam interna e externamente por meio de processos específicos, no qual pode-se distinguir um ou mais elementos que indicam identidade e coesão social, cultural e territorial. (MDA, 2003, p. 20)

Sob essa dimensão territorial, o desenvolvimento deve ser compreendido como um processo multidimensional, que reflete a interação social, econômica, política, institucional, cultural e ambiental. Perante essa complexidade, as estratégias territoriais de desenvolvimento devem buscar atingir objetivos múltiplos e integrais para atender às principais demandas dos atores sociais em uma determinada territorialidade (WESZ JUNIOR, 2005).

Para Schneider (2004), a abordagem territorial do desenvolvimento no Brasil tem se tornado notória, principalmente, no âmbito do planejamento de políticas públicas. Dentre os fatores ou motivos que levaram à emergência da abordagem territorial do desenvolvimento, esse autor destaca o esgotamento teórico e prático 
da abordagem regional, que torna evidente os limites da noção de região como unidade de referência para se pensar as ações e políticas públicas destinadas à promoção do desenvolvimento.

De um modo geral, Schneider (2004) destaca que a noção de região sempre esteve atrelada às características naturais (relevo, clima, geologia, localização, entre outras) que eram utilizadas como referências para estimar, medir e comparar a eficiência econômica com que os homens faziam uso desses recursos naturais. De acordo com Mendonça e Ortega (2005), a formulação e a implantação de projetos de desenvolvimento calcadas na noção de região eram desvinculadas da diversidade econômica, social e política desses territórios.

Contudo, a partir de meados da década de 70 e, mais especificamente, durante a década de 80, novos critérios de julgamento e avaliação do que poderia ser definido como desenvolvimento, tais como as noções de sustentabilidade ambiental e qualidade de vida, passaram a vigorar e a se legitimar. Perante esses novos critérios sobre desenvolvimento, a abordagem regional foi perdendo seu poder explicativo, enquanto referência teórica e conceitual, e tornou-se insuficiente como instrumento para o planejamento normativo das ações práticas do Estado e dos agentes políticos (SCHNEIDER, 2004).

É neste contexto que ganha relevância o território como uma nova unidade de referência para a atuação do Estado e a regulação das políticas públicas, pois permite a superação dos condicionantes e limites do aporte regional. Nessa perspectiva, a abordagem territorial assumiu a função de uma ferramenta para se pensar o planejamento e a intervenção no tecido social a partir de alguma escala, quer seja local, regional, microrregional. Dessa forma, o território passa a ser uma unidade de referência, um nível de operação e agregação adequado para operar o planejamento de ações governamentais e políticas públicas que promovam mudanças e transformações múltiplas no espaço social. Esta definição, segundo Schneider (2004), confere utilidade normativa e prática ao território, passando-se a entendê-lo como a unidade de referência para a implementação e gestão das ações intervencionistas, como é o caso do ZEE.

Conforme relata Wesz Junior (2005), a incorporação da abordagem territorial fez com que o desenvolvimento fosse compreendido além dos limites naturais dos recursos, que passaram a ser conjugados com as condições sociais, econômicas e políticas do território. Dentre os pontos de referência para o desenvolvimento na abordagem territorial, Wesz Junior (2005) e Petter, R., Petter, V. e Quadros (2007) destacam: o econômico (competitividade territorial); o sociocultural (equidade e diversidade); o ambiental (gestão dos recursos naturais); o político e institucional (democracia e cidadania). Além disso, esses autores também salientam a necessidade de se reconhecer a diversidade dos problemas e das soluções locais para a política e a prática de gestão do território.

Em outras palavras, Beduschi Filho e Abramovay (2003) ressaltam que a gestão territorial não consiste em redistribuir recursos e riquezas já criadas e existentes, mas ao contrário, em despertar os potenciais para a criação de riquezas, iniciativas e coordenações novas. Dessa forma, observa-se a necessidade de se reconhecer as especificidades de cada território, e ofertar instrumentos de desenvolvimento que atendam a essas características. Corroborando com essa colocação, Vidal (2004) destaca a importância da gestão territorial nos municípios, regiões, estados ou nações, visto que na prática, as características do território têm sido protagonistas na análise de novos investimentos, bem como para a atração e manutenção de novos negócios e/ou novas empresas.

Perante todas as colocações apresentadas sobre esse instrumento de gestão territorial, vale ressaltar que o termo aqui adotado na condução do ZEE aplicado no estado de Minas passa, fundamentalmente, pelo processo de identificação das vulnerabilidades naturais e das potencialidades sociais desse território. Nesse sentido, todos os resultados apresentados na (vírgula próxima seção têm como finalidade mostrar sua aplicabilidade como instrumento de gestão social do território e, especificamente, do território da cidadania do noroeste de Minas Gerais. 


\section{Categorias de Potencialidade Social dos Municípios Mineiros}

É importante ressaltar que as informações apresentadas como resultados da potencialidade social do ZEEMG devem ser consideradas em seu conjunto e não de forma fragmentada ou isolada. As informações utilizadas, para compor o banco de dados da potencialidade social, encontram-se no ZEE-MG de forma articulada, o que permite visualizar a realidade social de forma mais ampla. É esta articulação de informações que constitui a base de formação do Índice de Potencialidade Social. Por outro lado, é também importante considerar a dinamicidade que está contida na formação do Índice de Potencialidade Social, no sentido de permitir sempre a atualização do banco de dados, buscando acompanhar as mudanças sociais muito próximas dos fatos e acontecimentos de cada município e no conjunto do estado de Minas Gerais. Desta forma, assim que se atualizar uma base de dados, a potencialidade pode sofrer alterações e mostrar as mudanças na realidade social de cada município, tanto para melhor quanto para pior. Esse aspecto torna o ZEE um instrumento dinâmico e democrático de gestão e de grande utilidade para o CODETER e para todos os atores envolvidos com o desenvolvimento territorial.

Com base no Banco de Dados do ZEE-MG foram geradas tabelas com a relação dos 853 municípios, contendo a categorização (A, B, C, D, E) resultante do Índice de Potencialidade Social (IPS), a categorização correspondente a cada componente (produtivo, natural, humano e institucional), bem como a cada fator condicionante e a cada indicador. Estes resultados expressam, no todo e em cada parte, uma combinação específica da categorização de cada município. Assim, um município que obteve a categoria A no IPS pode apresentar uma combinação de categorias que não seja integralmente $\mathbf{A}$ em todos os componentes. Pode, por exemplo, apresentar uma combinação A no componente Produtivo, C no componente Natural, A no componente Humano e B no componente Institucional. Da mesma forma, um município que obteve a categoria B no IPS pode apresentar combinações específicas ao nível dos componentes, dos fatores condicionantes e dos indicadores e, assim, sucessivamente até a categoria $\mathbf{E}$. Apresentaremos aqui a síntese desses resultados por região do estado de Minas Gerais.

Com base na metodologia e no Banco de Dados disponível, foram obtidos os resultados gerais de classificação para todos os municípios mineiros, levando-se em consideração os pesos atribuídos a cada indicador utilizado de acordo com a aplicação do método de análise multivariada por componentes principais, estabelecendo-se cinco intervalos "percentílicos" para cada indicador de acordo com a variabilidade dos dados. O resultado da aplicação deste método estatístico revelou os pesos específicos para cada indicador e para cada componente, como pode ser observado na Tabela 1.

Dentre os quatro componentes da potencialidade social, destacam-se os componentes "humano" e "institucional" com maior peso. Os dois pesos somados chegam a 78\%, o que é bastante significativo na composição final da potencialidade social. Isto significa que a presença das instituições públicas e as condições sociais dos cidadãos refletem decisivamente na potencialidade social dos municípios mineiros. 
Tabela 1

Componentes e Indicadores da potencialidade social, ZEE-MG, 2007

\begin{tabular}{|c|c|c|}
\hline COMPONENTES/INDICADORES & $\begin{array}{c}\text { Peso } \\
\text { Absoluto }\end{array}$ & Peso \% \\
\hline Produtivo & & 15,28 \\
\hline 1.1.1 Índice da malha rodoviária & 0,100781 & 1,02 \\
\hline 1.1.2 Índice transporte aéreo & 0,183099 & 3,35 \\
\hline 1.1.3 Índice da malha ferroviária & 0,112006 & 1,25 \\
\hline 1.2.1 Índice do VA Agropecuário 2004 & 0,141561 & 2,00 \\
\hline 1.2.2 Índice do VA Indústria 2004 & 0,177188 & 3,14 \\
\hline 1.2.3 Índice do VA Serviços de 2004 & 0,156917 & 2,46 \\
\hline 1.2.7.1 Índice das exportações de 2006 & 0,143127 & 2,05 \\
\hline Natural & & 6,26 \\
\hline 2.1.1 Densidade de Ocupação dos Solos & 0,081617 & 0,67 \\
\hline 2.1.2 Indicador do nível tecnológico da agropecuária (ha) & 0,143921 & 2,07 \\
\hline 2.2.1 Índice de concentração fundiária invertido & 0,053856 & 0,29 \\
\hline 2.2.2 Índice de Agricultores Familiares & 0,168272 & 2,83 \\
\hline 2.3.1 Índice CFEM & 0,060427 & 0,37 \\
\hline 2.4.1 Índice ICMS Ecológico - Área Conservação & 0,020093 & 0,04 \\
\hline Humano & & 43,45 \\
\hline 3.1.1 Taxa de Ocupação & 0,098871 & 0,98 \\
\hline 3.1.2 Taxa de Desocupação Invertida & 0,021762 & 0,05 \\
\hline 3.2.1 Emprego formal & 0,190175 & 3,62 \\
\hline 3.2.2 Distribuição Espacial da População (\%pop urbana) & 0,228391 & 5,22 \\
\hline 3.2.3 Razão de dependência invertida & 0,217201 & 4,72 \\
\hline
\end{tabular}




\begin{tabular}{|l|c|c|}
\hline 3.3.1 Renda & 0,281603 & 7,93 \\
\hline 3.3.2 Educação & 0,259172 & 6,72 \\
\hline 3.3.3 Habitação & 0,208228 & 4,34 \\
\hline 3.3.4 Saúde & 0,147497 & 2,18 \\
\hline 3.3.5 Saneamento & 0,091160 & 0,83 \\
\hline 3.3.6.1 Taxa invertida de crimes violentos (2006) & 0,026085 & 0,07 \\
\hline 3.3.7 Índice de Desenvolvimento Humano Municipal - IDH-M (2000) & 0,261166 & 16,22 \\
\hline \multicolumn{1}{|c|}{ Institucional } & & 35,00 \\
\hline 4.1.1 Capacidade Institucional & 0,218340 & 4,77 \\
\hline 4.1.2 Gestão do Desenvolvimento Rural & 0,039322 & 0,15 \\
\hline 4.1.3 Gestão Ambiental Municipal & 0,136537 & 1,86 \\
\hline 4.1.4 Gestão Cultural & 0,230943 & 5,33 \\
\hline 4.2.1 Organizações Jurídicas & 0,115161 & 1,33 \\
\hline 4.3.1 Organizações Financeiras & 0,171502 & 2,94 \\
\hline 4.4.1 Organizações de Fiscalização e Controle & 0,213766 & 4,57 \\
\hline 4.5.1 Organizações de Ensino Superior e Ensino Profissionalizante & 0,223918 & 5,01 \\
\hline 4.5.3 Organizações de Pós-Graduação e Pesquisa & 0,139160 & 1,94 \\
\hline 4.6.1 Unidades de defesa social & 0,192768 & 3,72 \\
\hline 4.6.2 Capacidade de Aplicação da Lei & 0,183888 & 3,38 \\
\hline
\end{tabular}

Fonte: Pereira (2008a).

Por um lado, a presença das instituições representa a possibilidade de acesso do cidadão à informação, saúde, justiça, educação, cultura, segurança, aos recursos materiais e financeiros de que necessita para alcançar e valer seus direitos, no âmbito de uma sociedade democrática e de um Estado de direito. Por outro lado, as condições sociais representam os graus ou níveis da situação de vida em que se encontram os cidadãos dentro de seus municípios em termos de emprego, renda, escolaridade, habitação, saúde, longevidade, dentre outros. O maior peso atribuído ao componente humano está coerente com a sua importância e finalidade, pois representa o "termômetro" da qualidade de vida dos cidadãos, de forma que os outros componentes 
servem de base para que as pessoas possam alcançar os melhores índices de condições sociais. Assim, as instituições, os recursos naturais do ponto de vista econômico e a infraestrutura produtiva constituem os meios para alcançar a melhor qualidade de vida da população refletida no componente humano.

Esse aspecto reforça a consideração de Sen (2000) de que não se pode dizer e argumentar, teórica e empiricamente, que a renda ou o PIB (Produto Interno Bruto) deve ser a melhor medida de desenvolvimento sustentável de um município ou de um país. A tese de Sen (2000) é que desenvolvimento deve ser pensado e praticado como um processo de expansão das liberdades reais que os cidadãos devem desfrutar. $\mathrm{O}$ crescimento econômico, neste caso, tem sua importância apenas como um dos meios para se alcançar o desenvolvimento sustentável. Assim, esse autor trata da renda apenas como uma das esferas do desenvolvimento que, dentre outras, deve envolver um processo igualitário e democrático.

Nessa perspectiva, o componente humano sinaliza relevante condição para a análise da própria potencialidade social e para o desenvolvimento sustentável dos municípios mineiros. O componente humano, aliado ao componente institucional, constitui, neste caso, medida de valor imprescindível, tanto para identificar e analisar o alcance de melhores níveis de condições de vida da população quanto para identificar e analisar os graus e níveis de exclusão social. Este último aspecto adquire importância relativa em termos de potencialidade social, e está fundamentado nas considerações que Pochmann, Barbosa, Campos et al. (2004, p. 45) fazem em relação às novas formas de exclusão: "Além da pobreza absoluta, da fome e do analfabetismo, novas formas de exclusão ganham destaque, associadas à crescente desigualdade, precarização do mercado de trabalho (desemprego e informalidade), expansão da violência urbana e novas epidemias. Paralelamente, emerge uma novíssima forma de exclusão, aquela relacionada à falta de acesso ao novo padrão tecnológico: a exclusão digital".

Essas considerações sinalizam a importância dos indicadores sociais para a gestão social e para a gestão pública na direção do desenvolvimento sustentável. Neste sentido, vale ressaltar que tais indicadores não devem ser tratados de forma isolada, mas no conjunto, no sentido de ampliar o conhecimento científico sobre a realidade que está sendo estudada.

A partir desses resultados, os municípios poderão ser aglomerados por categoria, formando zonas dentro de cada região, em termos de ponto de partida para o desenvolvimento sustentável de condições Muito Favoráveis (A), Favoráveis (B), Pouco Favoráveis (C), Precárias (D) e Muito Precárias (E) de potencialidade social. Na verdade, cada categoria representa uma Situação Atual específica, pois constitui o resultado da conjugação dos indicadores utilizados. Assim, podem-se avaliar, de forma geral e específica, os municípios situados em uma mesma categoria e em uma mesma região, avaliando-se as desigualdades locais. Uma avaliação em termos gerais pode ser feita da seguinte forma:

\section{a) Situação atual dos municípios da categoria $\mathrm{A}$}

Representa todos os municípios que possuem condições gerais semelhantes, como ponto de partida muito favorável para o desenvolvimento sustentável, em comparação com todos os municípios do estado de Minas Gerais. Esta situação se traduz na capacidade que os municípios possuem de gerar desenvolvimento sustentável a partir do ponto em que se encontra em termos produtivos, naturais, humanos e institucionais. Os municípios que se encontram nesta categoria possuem maior vantagem comparativa a outros municípios, por disporem de maiores recursos. No entanto, suas possibilidades objetivas não se esgotaram pelo fato de se encontrarem nesta categoria, pois a concepção de desenvolvimento sustentável está fundamentada em um processo social dinâmico, ou seja, em transformação. 


\section{b) Situação atual dos municípios da categoria B}

Representa todos os municípios que possuem condições gerais semelhantes, como ponto de partida favorável para o desenvolvimento sustentável, em comparação com todos os municípios do estado de Minas Gerais. Esta situação se traduz na menor capacidade que possuem em relação aos que se encontram na categoria A, mas estão acima da média dos municípios do estado em termos de capacidade de gerar desenvolvimento sustentável, o que lhes conferem possibilidades objetivas de se desenvolverem com os próprios recursos de que dispõem em termos produtivos, naturais, humanos e institucionais. Portanto, são municípios que possuem capacidades próprias de gerar desenvolvimento, desfrutam de estrutura e de autonomia para isso. Podem responder favoravelmente, ao serem estimulados por políticas públicas e por investimentos setoriais voltadas para o desenvolvimento local.

\section{c) Situação atual dos municípios da categoria C}

Representa todos os municípios que possuem condições gerais semelhantes, como ponto de partida pouco favorável para o desenvolvimento sustentável, em comparação com todos os municípios do estado de Minas Gerais. Esta situação se traduz na capacidade limitada que possuem de gerar desenvolvimento sustentável, pois se encontram na média do estado em termos de potencialidade social. Nesta categoria, os municípios estão na liminaridade, ou seja, podem melhorar ou piorar de posição em termos de condições produtivas, naturais, humanas e institucionais. Podem se tornar autônomos ou dependentes de outros municípios, do estado ou da federação. Portanto, são municípios que possuem capacidades limitadas, e precisam ser estimulados por políticas públicas voltadas para superar os problemas que os colocam nesta categoria.

\section{d) Situação atual dos municípios da categoria D}

Representa todos os municípios que possuem condições gerais semelhantes, como ponto de partida precário para o desenvolvimento sustentável, em comparação com todos os municípios do estado de Minas Gerais. Esta situação se traduz na capacidade muito limitada que possuem de gerar desenvolvimento, no entanto, possuem capacidades que devem ser estimuladas para conseguirem superar os seus principais problemas. São municípios que dependem de outros municípios, do estado ou da federação para que possam cumprir com suas obrigações sociais, econômicas e institucionais. Portanto, são municípios que possuem necessidades básicas que precisam ser suprimidas para se desenvolverem, mas não deixam de possuir capacidades importantes para gerarem desenvolvimento sustentável. Precisam ser estimulados por políticas públicas e por investimentos fortes em setores básicos de desenvolvimento local.

\section{e) Situação atual dos municípios da categoria E}

Representa todos os municípios que possuem condições gerais semelhantes, como ponto de partida muito precário para o desenvolvimento sustentável, em comparação com todos os municípios do estado de Minas Gerais. Esta situação se traduz na capacidade extremamente limitada que possuem de gerar desenvolvimento sustentável, pois suas necessidades são tão básicas que se encontram na dependência de outros municípios, do estado ou da federação para resolvê-los. Nesta situação se encontram aqueles municípios dependentes ou denominados de "previdenciários", pois sua condição produtiva, humana, natural e institucional não é suficiente para atender às demandas de sua própria população e dependem das transferências diretas dos níveis de governo estadual e federal, como é o caso dos repasses de recursos previdenciários. Portanto, são municípios dependentes de assistência direta e constante do governo do estado ou do governo federal em áreas muito básicas de desenvolvimento. 
Na Tabela 2 consta a síntese dos resultados da categorização dos municípios em cada uma das regiões do estado de Minas Gerais e o total de municípios por região e por categoria. Nas tabelas e cartas apresentadas a seguir estão contidos os resultados da potencialidade social pela combinação dos quatros componentes, a frequência da quantidade de municípios por categorias de potencialidade social, bem como os resultados dos municípios com suas respectivas categorias de potencialidade social por região. Ao observar a Tabela 2 e a Figura 1, podem-se analisar vários aspectos da potencialidade social dos municípios e, especialmente, a situação comparativa entre regiões do estado de Minas Gerais, destacando-se a região noroeste.

Tabela 2

Frequência da potencialidade social dos municípios, por categoria e por região de Minas Gerais, ZEE-MG, 2007

\begin{tabular}{|l|l|l|l|l|l|c|}
\hline \multirow{2}{*}{ Regiões, segundo COPAM } & \multicolumn{5}{|c|}{ Categorias } & \multirow{2}{*}{$\begin{array}{c}\text { Número de municípios por } \\
\text { região }\end{array}$} \\
\cline { 2 - 7 } & A & B & C & D & E & 60 \\
\hline Alto São Francisco & 21 & 20 & 17 & 2 & - & 84 \\
\hline Central & 29 & 20 & 16 & 15 & 4 & 56 \\
\hline Jequitinhonha & 1 & 1 & 5 & 12 & 37 & 135 \\
\hline Leste & 10 & 9 & 16 & 49 & 51 & 22 \\
\hline Noroeste & 5 & 5 & 3 & 5 & 4 & 90 \\
\hline Norte & 3 & 3 & 3 & 23 & 58 & 177 \\
\hline Sul & 45 & 62 & 50 & 17 & 3 & 67 \\
\hline Triângulo & 39 & 24 & 4 & - & - & 162 \\
\hline Zona da Mata & 18 & 26 & 57 & 47 & 14 & 853 \\
\hline Totalização & 171 & 170 & 171 & 170 & 171 & $\mathbf{2 1}$ \\
\hline
\end{tabular}

Fonte: Pereira (2008a).

Na região noroeste do estado de Minas Gerais, em destaque na Tabela 2, não há predominância de municípios em uma categoria específica. $\mathrm{O}$ que se observa é uma distribuição muito equilibrada do número de municípios entre as cinco categorias de potencialidade social. No entanto, ao somar o número de municípios das categorias A, B e C de potencialidade social chega-se a $60 \%$ dos municípios, o que caracteriza esta região em condições precárias a pouco favoráveis de potencialidade social. Portanto, é uma

${ }^{6}$ Câmara de Política Ambiental de Minas Gerais (COPAM-MG). 
região peculiar, mas caracteristicamente em condições pouco favoráveis de potencialidade social. Esta situação representa a capacidade limitada que possuem de promover seu próprio desenvolvimento, necessitando de serem estimulados por políticas públicas e sociais e por investimentos fortes em setores básicos de desenvolvimento local, o que a justifica estar no Programa Território da Cidadania.

A Figura 1 expressa, na forma de carta, os resultados da potencialidade dos municípios observados na Tabela 2.

\section{Figura 1}

\section{Carta de potencialidade social dos municípios do estado de Minas Gerais, ZEE-MG, 2007}

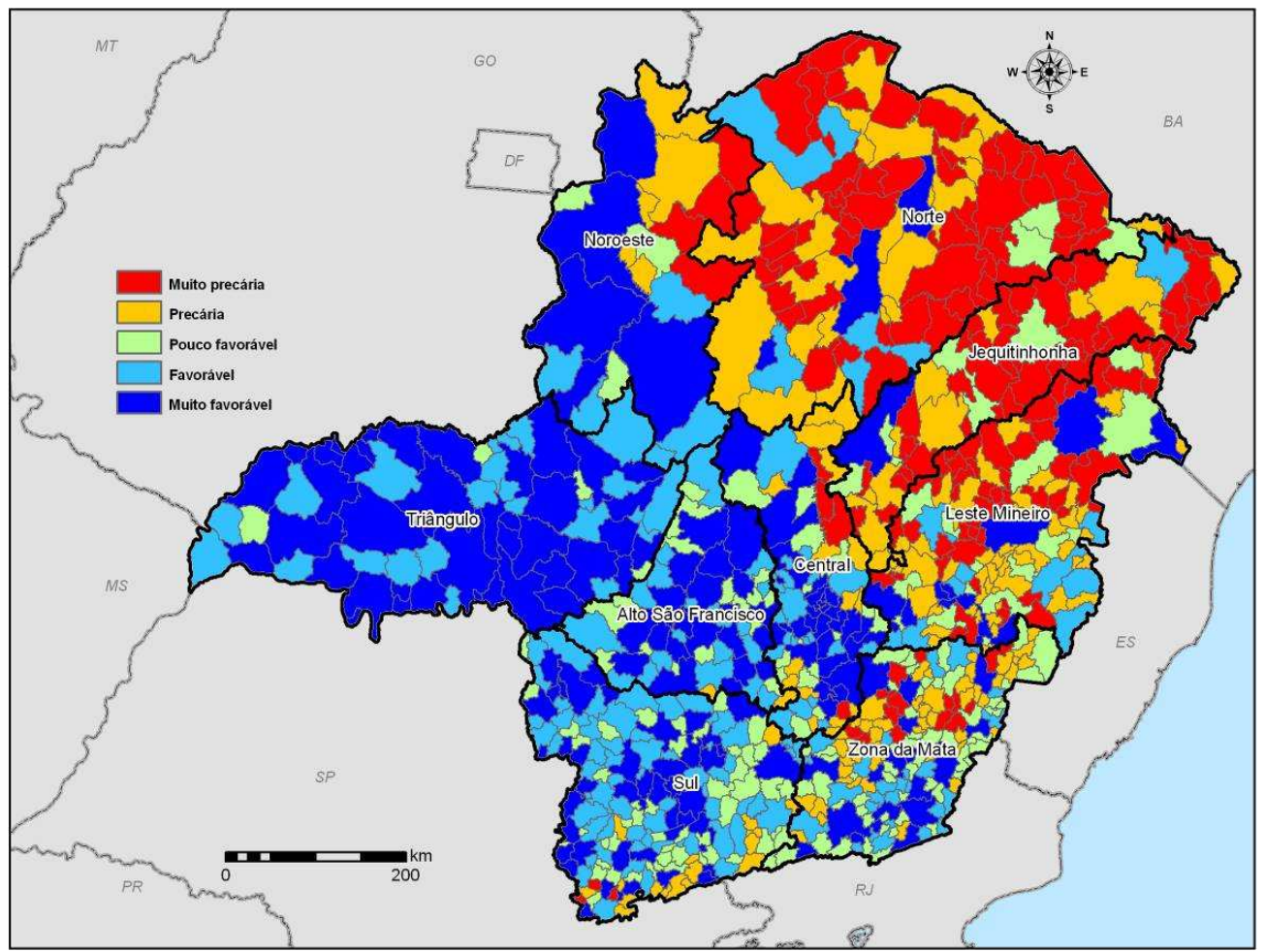

Fonte: Pereira (2008b).

Pode-se observar na Figura 1, claramente, as desigualdades em termos de potencialidade social na região noroeste de Minas Gerais, bem como o que ocorre no restante do estado. A carta de potencialidade social da região noroeste do estado de Minas Gerais está, praticamente, dividida ao meio, entre os municípios de potencialidade favorável e não-favorável ou precária. Os cinco municípios com potencialidade muito favorável estão representados pela cor azul-escura. Estes municípios são também os municípios de maior destaque na região, como João Pinheiro, Paracatu e Vazante, pois congregam em seu interior bons indicadores de potencialidade social e, por isso, são demandados pelos municípios vizinhos em termos de acesso à infraestrutura produtiva, a instituições e a melhores condições sociais, como educação e saúde, por exemplo.

Além destes municípios com condições muito favoráveis, existem outros cinco municípios com condições favoráveis de potencialidade social, representados pela cor azul-clara. Vale ressaltar que todos eles são 
municípios localizados próximos aos municípios de potencialidade muito favorável, o que pode denotar uma certa influência de um município em relação ao outro. No entanto, há oito municípios de potencialidade precária a muito precária, representados pela cor laranja e vermelha. Estes municípios estão mais próximos das três regiões mais precárias em termos de potencialidade social no estado de Minas Gerais, quais sejam: Norte, Jequitinhonha e Leste Mineiro. No meio destes 22 municípios observam-se três municípios em verde, apresentando condições pouco favoráveis de potencialidade social.

Os resultados expressos nesta carta e as informações geradas pelo banco de dados mostram que os municípios em condições de potencialidade mais favoráveis sofrem pressões sociais, econômicas e políticas daqueles municípios que partem de condições precárias de potencialidade social. As manchas mais fortes em azul representam, geralmente, municípios de porte médio a grande, considerados municípios polos onde se encontram instituições públicas, hospitais, universidades, centros tecnológicos, indústrias, centros comerciais, infraestrutura e atividades econômicas de importância regional. As populações dos municípios do entorno, geralmente, procuram atendimento nestes municípios, seja no âmbito da saúde, da educação, das instituições públicas, seja no âmbito do comércio, do emprego e de atividades econômicas.

\section{Territórios da Cidadania: o Noroeste de Minas Gerais}

Diante da complexidade e problemática territorial, devem-se avaliar todas as esferas sociais que afetam as dimensões do desenvolvimento, como afirma Cardoso Junior $(2009$, p.101): é "necessário lembrar que o desenvolvimento tem de ser global, ou seja, desenvolvimento economicamente sustentado (ao longo do tempo), socialmente includente, politicamente moderno e ambientalmente sustentável".

Para o desenvolvimento territorial, o governo federal brasileiro subdividiu sete linhas de concentração em programas. Assim, as Ações Fundiárias foram alocadas em 11 programas; Apoio à Gestão Territorial em 9 programas; Direitos e Desenvolvimento Social em 12 programas; Educação e Cultura em 32 programas; Infraestrutura em 13 programas; Organização Sustentável da Produção em 76 programas; Saúde, Saneamento e Acesso à Água, em 27 programas. Contudo, a implantação e articulações destes programas implicam substanciais mudanças estruturais, sobretudo no tocante à participação ativa da sociedade e representantes do Estado nas diferentes instâncias governamentais. Acresce a isto o fato de que essa segmentação das linhas em programas poderá facilitar e conferir maior efetividade à implementação, conforme demanda e necessidades dos territórios.

Para que o desencadeamento do programa Territórios da Cidadania ocorra, é necessário, além de investimentos financeiros, estratégias coerentes e eficazes que procurem estimular, e efetivar as potencialidades sociais em seus diferentes componentes: produtivo, natural, humano e institucional.

Territórios da cidadania constituem-se em um esforço do governo federal brasileiro em planejar o desenvolvimento do país de modo a reduzir as desigualdades regionais, em uma perspectiva de sustentabilidade e de promoção da cidadania. Assim, a Política Nacional de Desenvolvimento Sustentável dos Povos e Comunidades Tradicionais do governo brasileiro, segundo o Decreto 6.040 de 07 de fevereiro de 2007, prevê em seu art. $3^{\circ}$, inciso II (BRASIL, 2007) como: "II - Territórios Tradicionais: os espaços necessários à reprodução cultural, social e econômica dos povos e comunidades tradicionais, sejam eles utilizados de forma permanente ou temporária, observado, no que diz respeito aos povos indígenas e quilombolas [...]”.

Ao se identificar e caracterizar as potencialidades dos municípios, consegue-se estabelecer dimensões territoriais na busca de acelerar o processo de desenvolvimento dos territórios. Para a demarcação e inclusão 
destes territórios no programa Território da Cidadania, foram considerados alguns aspectos como: Menor IDH (Índice de Desenvolvimento Humano) territorial; maior concentração de beneficiários do Programa Bolsa Família; maior concentração de agricultores familiares e assentados da reforma agrária; maior concentração de populações tradicionais, quilombolas e indígenas; e baixo dinamismo econômico, segundo a tipologia das desigualdades regionais indicadas na Política Nacional de Desenvolvimento Regional (PNDR), do Ministério da Integração.

O território do noroeste de Minas Gerais, conforme o IBGE (2010), é formado por 22 municípios, dos quais, o de menor população é Natalândia com 3.288 habitantes, e os maiores são Paracatu e João Pinheiro com 84.687 e 45.260 , respectivamente, sendo que os demais municípios possuem menos de 20.000 habitantes.

No sentido de que os territórios da cidadania desenvolvam as potencialidades sociais dos municípios e neutralizem a desigualdade, o governo federal tem alocado recursos financeiros no apoio a atividades produtivas, promoção da cidadania e de direitos, bem como na infraestrutura básica. Na Tabela 3, observamse dados sobre o montante dos recursos financeiros investidos nos anos 2008 a 2010 no Território do Noroeste de MG, em comparação com o que foi investido nos demais territórios do programa em Minas Gerais, conforme o Portal Brasil (2010).

Tabela 3

Investimentos realizados de 2008 até 31/10/2010 na região noroeste de MG.

\begin{tabular}{|l|r|r|r|r|}
\hline \multicolumn{1}{|c|}{ Território } & \multicolumn{1}{c|}{$\begin{array}{c}\text { Apoio a } \\
\text { Atividades } \\
\text { Produtivas }\end{array}$} & Cidadania e Direitos & Infraestrutura & \multicolumn{1}{c|}{ Total } \\
\hline Noroeste de Minas & $154.864 .441,85$ & $213.292 .394,33$ & $100.761 .732,03$ & $\mathbf{4 6 8 . 9 1 8 . 5 6 8 , 2 1}$ \\
\hline $\begin{array}{l}\text { Outros Territórios de } \\
\text { MG }\end{array}$ & $546.707 .053,20$ & $1.371 .205 .362,44$ & $282.758 .177,85$ & $\mathbf{2 . 2 0 0 . 6 7 0 . 5 9 3 , 4 9}$ \\
\hline Total & $\mathbf{7 0 1 . 5 7 1 . 4 9 5 , 0 5}$ & $\mathbf{1 . 5 8 4 . 4 9 7 . 7 5 6 , 7 7}$ & $\mathbf{3 8 3 . 5 1 9 . 9 0 9 , 8 8}$ & $\mathbf{2 . 6 6 9 . 5 8 9 . 1 6 1 , 7 0}$ \\
\hline
\end{tabular}

Fonte: Portal Brasil (2010), adaptado pelos autores.

A destinação dos investimentos realizados de 2008 a 2010 no território do noroeste de Minas Gerais foi distribuída da seguinte forma: cerca $22,07 \%$ a atividades produtivas; $13,46 \%$ a cidadania e direitos; e $26,27 \%$, em infraestrutura totalizando, aproximadamente, $17,57 \%$ de todo investimento aplicado nessas três áreas, comparando-se com o restante dos territórios do programa situados em Minas Gerais.

As estratégicas de investimentos destinadas aos territórios variam conforme prioridades percebidas pelo governo, assim o restante dos $82,43 \%$ foram aplicados entre os sete territórios: Alto Jequitinhonha, constituída por 20 municípios, Alto Rio Pardo com 15 cidades, Baixo Jequitinhonha com 16, Médio Jequitinhonha com 19, Serra Geral com 16, Sertão de Minas com 17 e Vale do Mucuri com 27 cidades. Observa-se que o Território das Águas Emendadas - DF/GO/MG (Distrito Federal/ Goiás/ Minas Gerais) composto por 11 municípios - apesar de ser integrante do Território Noroeste de Minas não foi citado no respectivo balanço apresentado pelo governo. Além da composição com esses municípios, o território noroeste de Minas Gerais conta com uma estrutura de coordenação colegiada das ações públicas. 
Segundo Favareto (2010, p. 94-95), “a criação dos colegiados territoriais, Codeter, converteu-se num eixo central da implementação da política, uma vez que esta estrutura institucional significa a base de participação e representação dos atores sociais locais, o cenário de concertação e negociação, o núcleo central dos processos de planejamento, a instância de controle social e o suporte político para a sustentabilidade de longo prazo da estratégia". Os Codeter constituem espaços sociais fundamentais da representação social e da dialogicidade entre os atores sociais participantes do processo de desenvolvimento territorial. É um espaço de poder decisório democrático e de exercício da cidadania, onde ações e investimentos públicos são discutidos e acordados, como é característico de um processo de gestão social. Na verdade, os CODETER constituem o ponto de partida para a formação da esfera pública, espaço onde a gestão social pode se desenvolver plenamente. É por meio dos Conselhos, constituídos de forma paritária entre sociedade civil organizada e poder público do Estado, que as questões estratégicas do desenvolvimento territorial são decididas sem a interferência político-partidária e sem a intervenção do poder tradicional local. De acordo com Favareto (2010), os CODETER se sustentam na concepção multidimensional de desenvolvimento com base nos princípios de representatividade, diversidade e pluralidade, pois encontram-se em sua estrutura interna uma ampla gama de grupos de interesse, de instituições públicas e de organizações sociais. Assim, segundo Favareto (2010, p. 96), "a estrutura interna dos Codeter, embora apresente diferenças regionais, tem seguido uma organização composta de assembleia geral, um grupo diretor, um núcleo técnico e câmaras temáticas, cada uma com uma secretaria”. Esse autor destaca a importância do núcleo técnico pela necessidade de reunir a capacidade pública existente nos Territórios, e de congregar uma rede de entidades sociais interessadas no desenvolvimento do próprio Território.

Assim, procuramos mostrar os resultados do ZEE-MG que caracterizam os 22 municípios que fazem parte do território noroeste. No Quadro 3, são apresentados os índices de potencialidade social como condições muito favoráveis até muito precárias dos 22 municípios representados pelas letras maiúsculas A, B, C, D e E, conforme já mencionado.

Quadro 3

Potencialidades sociais dos municípios do território do noroeste de MG

\begin{tabular}{|l|c|c|c|c|c|}
\hline \multirow{2}{*}{ Municípios } & \multirow{2}{*}{$\begin{array}{c}\text { Potencialidade } \\
\text { Social }\end{array}$} & \multicolumn{4}{c|}{ Potencialidade social dos componentes } \\
\cline { 3 - 6 } & Produtivo & Natural & Humano & Institucional \\
\hline Arinos & D & B & B & E & B \\
\hline Bonfinópolis de Minas & C & B & A & D & B \\
\hline Brasilândia de Minas & B & A & B & C & C \\
\hline Chapada Gaúcha & E & B & E & E & C \\
\hline Dom Bosco & D & E & C & D & E \\
\hline Formoso & D & A & A & E & C \\
\hline Guarda-Mor & B & B & A & B & C \\
\hline João Pinheiro & A & A & B & C & A \\
\hline
\end{tabular}




\begin{tabular}{|c|c|c|c|c|c|}
\hline Lagamar & B & C & B & B & $\mathrm{C}$ \\
\hline Lagoa Grande & $\mathrm{C}$ & C & A & C & $\mathrm{D}$ \\
\hline Natalândia & $\mathrm{D}$ & D & $\mathrm{C}$ & $\mathrm{D}$ & $\mathrm{E}$ \\
\hline Paracatu & $A$ & $A$ & $A$ & B & $A$ \\
\hline Pintópolis & $E$ & $\mathrm{C}$ & $E$ & $\mathrm{E}$ & $\mathrm{D}$ \\
\hline Presidente Olegário & B & $A$ & A & B & B \\
\hline Riachinho & $\mathrm{E}$ & $\mathrm{C}$ & C & $\mathrm{E}$ & $\mathrm{E}$ \\
\hline Santa Fé de Minas & $E$ & $\mathrm{C}$ & $\mathrm{E}$ & $E$ & $\mathrm{C}$ \\
\hline São Gonçalo do Abaeté & B & B & B & $\mathrm{C}$ & B \\
\hline São Romão & $\mathrm{D}$ & $\mathrm{C}$ & $E$ & $\mathrm{E}$ & A \\
\hline Uruana de Minas & $\mathrm{D}$ & B & $A$ & $E$ & $\mathrm{D}$ \\
\hline Urucuia & $\mathrm{E}$ & $A$ & $\mathrm{E}$ & $E$ & $\mathrm{C}$ \\
\hline Varjão de Minas & B & B & B & B & B \\
\hline Vazante & A & B & B & A & A \\
\hline
\end{tabular}

Fonte: Pereira (2008b).

Entre os componentes que integram o índice da potencialidade social dos municípios do território noroeste, destaca-se o humano com o maior número de municípios na categoria $\mathrm{E}$, como mostra a Tabela 4. Percebese, portanto, que os municípios classificados como precários e muito precários em termos de potencialidade social no componente constituem um dos grandes desafios para a gestão do território, já que esse componente influencia diretamente todos os demais. Esses resultados e os diagnósticos e planos realizados pelo CODETER no território noroeste de Minas Gerais potencializam com informações e conhecimento da realidade todos os atores sociais envolvidos na gestão social desse território. Dessa forma, os gestores sociais poderão definir estratégias e metas de superação dos fatores que causam as grandes desigualdades verificadas no âmbito do território. 
Tabela 4

\section{Distribuição dos municípios do território do noroeste de Minas Gerais segundo os componentes da Potencialidade Social}

\begin{tabular}{|c|c|c|c|c|c|c|c|}
\hline \multicolumn{2}{|c|}{$\begin{array}{l}\text { Componente } \\
\text { Produtivo }\end{array}$} & \multicolumn{2}{|c|}{$\begin{array}{c}\text { Componente } \\
\text { Natural }\end{array}$} & \multicolumn{2}{|c|}{$\begin{array}{c}\text { Componente } \\
\text { Humano }\end{array}$} & \multicolumn{2}{|c|}{ Componente Institucional } \\
\hline Categoria & $\begin{array}{c}\text { № } \\
\text { Municípios }\end{array}$ & Categoria & $\begin{array}{c}\text { № } \\
\text { Municípios }\end{array}$ & Categoria & $\begin{array}{c}\text { № } \\
\text { Municípios }\end{array}$ & Categoria & $\begin{array}{c}\text { № } \\
\text { Municípios }\end{array}$ \\
\hline A & 6 & A & 7 & A & 1 & A & 4 \\
\hline B & 8 & B & 7 & B & 5 & B & 5 \\
\hline C & 6 & C & 3 & C & 4 & C & 7 \\
\hline D & 1 & D & 0 & D & 3 & D & 3 \\
\hline $\mathbf{E}$ & 1 & $\mathbf{E}$ & 5 & $\mathbf{E}$ & 9 & E & 3 \\
\hline
\end{tabular}

Fonte: Pereira (2008b), adaptado pelos autores.

Diante do exposto nestas duas últimas seções, percebe-se que as informações sobre o índice de potencialidade social e os componentes produtivo, natural, humano e institucional gerados pelo Zoneamento Ecológico-Econômico são essenciais para promover a gestão social e o desenvolvimento do território noroeste de Minas Gerais. É com base nesses resultados que os gestores sociais do território poderão identificar os problemas e suas causas, identificar demandas socioeconômicas e institucionais, pactuar uma agenda de ações, promover a integração de esforços dos atores presentes no território, promover o diálogo entre os atores sociais em torno de alternativas de desenvolvimento e de avaliação das ações públicas, bem como exercer o devido controle social sobre o Programa. Essas considerações estão relacionadas com o ciclo da gestão social proposto no Programa, conforme apresenta Favareto (2010, p. 97).

No marco da primeira área de resultado se estabeleceu o ciclo de gestão social, como roteiro orientador. Este ciclo se inicia com processos de sensibilização e mobilização dos atores sociais, na busca de que a ação coletiva se traduza na energia ou capital social. Isto conduz a uma fase de planejamento que inclui o diagnóstico territorial consensuado, a identificação de um projeto territorial de futuro e o estabelecimento de objetivos, diretrizes, estratégias e ações que irão ser desenvolvidas para alcançar as metas de desenvolvimento sustentável. A seguinte fase é a da organização, que compreende o fortalecimento das redes e organizações sociais para a articulação das alianças entre as organizações da sociedade civil e as instâncias gestoras da política pública, o fortalecimento dos arranjos institucionais e a divisão de responsabilidades no âmago dos colegiados. (FAVARETO, 2010, p. 97) 


\section{Considerações Finais}

É importante considerar que a combinação dos componentes produtivo, natural, humano e institucional do ZEE, expressa a categoria do município na sua forma quantitativa. A natureza qualitativa das informações que caracterizam cada município deve ser alvo de diagnósticos e pesquisas específicas, como foi contemplado, por exemplo, com o planejamento participativo do território noroeste de Minas Gerais realizado pelo CODETER. A partir dos indicadores de potencialidade social dos municípios mineiros é possível estabelecer relações entre gestão pública e gestão social no sentido de alcançar o desenvolvimento sustentável do território, ao se estabelecer ações sociais e políticas em conjunto, incluindo organizações sociais, públicas e privadas.

Os resultados da potencialidade social dos municípios mineiros correspondem à comparação dos dados do município em relação à média dos dados do estado de Minas Gerais. Portanto, novos estudos poderão ainda comparar os dados dos municípios da região noroeste de Minas, bem como os índices das demais regiões deste estado com a média dos dados do Brasil, contextualizando assim os municípios mineiros no cenário nacional em termos de potencialidade social, gestão territorial e englobando, consequentemente, as práticas de gestão social.

Contudo, o alcance deste trabalho está em difundir um instrumento de gestão social ainda desconhecido ou mesmo pouco utilizado pela gestão pública e pela gestão social, pois o ZEE constitui um excelente instrumento de gestão que poderá contribuir no curto e no médio prazo para a superação das desigualdades sociais, econômicas, culturais e ambientais em Minas Gerais e em outros estados da federação. Mostramos que isso é possível, ao se tomar como base o histórico dos indicadores dos quatro componentes do ZEE (produtivo, natural, humano e institucional), para pactuar uma agenda de ações públicas entre os diversos atores sociais presentes no território, no sentido de agir coletivamente para superar as desigualdades sociais historicamente determinadas. Consideramos que a gestão social deve contar com informações objetivas que mostrem, detalhadamente, a realidade do território para tomadas de decisões conscientes, como é o caso do conjunto de informações oferecidas pelo ZEE-MG.

Além disso, os resultados deste trabalho mostram as possibilidades efetivas de utilização do ZEE para os gestores de organizações públicas não-estatais, para gestores de organizações sociais, para gestores municipais e para gestores de empreendimentos privados, no sentido de se articularem em prol do desenvolvimento sustentável dos territórios da cidadania. Experiência que pode ser replicada em outros estados da federação e mesmo em outros países.

Contudo, há limites de utilização do ZEE, enquanto instrumento de gestão no que diz respeito aos resultados de natureza qualitativa, pois informações dessa natureza exigem estudos específicos e em profundidade em cada município e comunidade dentro do território, o que demanda tempo, pessoas qualificadas, recursos financeiros e materiais.

\section{Bibliografia}

ACSELRAD, H. O zoneamento ecológico-econômico e a multiplicidade de ordens socioambientais na Amazônia. Novos Cadernos NAEA, Vol. 3, $\mathrm{N}^{\circ} \quad 2,2000$. Brasília, DF. Disponível em: <http://www.naeaufpa.org/revistaNCN/ojs/viewarticle.php?id=52>. Acesso em 10 mar. 2011.

BECKER, B.; EGLER, C. Detalhamento da metodologia para execução do zoneamento ecológico-econômico pelos Estados da Amazônia Legal. Brasília: MMA, 1997. 
BEDUSCHI FILHO, L. C.; ABRAMOVAY, R. Desafios para a gestão territorial do desenvolvimento sustentável no Brasil. IN: CONGRESSO BRASILEIRO DE ECONOMIA E SOCIOLOGIA RURAL, 41, Juiz de Fora, Anais..., SOBER: Juiz de Fora, 2003.

BRASIL. Ministério do Meio Ambiente (MMA/SEDR). Programa Zoneamento Ecológico-Econômico: diretrizes metodológicas para o zoneamento ecológico-econômico do Brasil. 3 ed. Brasília: MMA/SEDR, 2006. Disponível em: < http://www.mma.gov.br/sitio/index.php?\%20ido=conteudo.monta\&idEstrutura=28\&idConteudo=8219\&idMenu=8781 >. Acesso em: 10 dez. 2010.

BRASIL. Decreto $\mathbf{n}^{\mathbf{6}} \mathbf{6 . 0 4 0}$, de $\mathbf{7}$ DE fevereiro de 2007. 2007. Disponível em: <http://www.planalto.gov.br/ccivil_03/_Ato2007-2010/2007/Decreto/D6040.htm>. Acesso em 10 mar. 2011

BRONZO, C. "Território como categoria de análise e como unidade de intervenção nas políticas públicas”. In.: FAHEL, M. \& NEVES, J. A. B. (Org.) Gestão e avaliação de políticas sociais no Brasil. Belo Horizonte, PUC Minas, 2007. 428p.

CARDOSO JUNIOR, J. C. (Org.) INSTITUTO DE PESQUISA ECONÔMICA APLICADA. Desafios ao desenvolvimento brasileiro: contribuições do conselho de orientação do Ipea. Brasília: IPEA, v.1, 2009. 285 p.

FAVARETO, A. Políticas de desenvolvimento territorial rural no Brasil: avanços e desafios. Brasília: IICA, 2010. (Série Desenvolvimento Rural Sustentável; v.12). 220p.

GIL, I. C. Territorialidade e desenvolvimento contemporâneo. Revista Nera, Presidente Prudente, ano 7, n. 4, jan./jul. 2004.

MENDONÇA, N. C.; ORTEGA, A. C. Estratégias de desenvolvimento territorial rural: governo FHC X governo Lula. In: CONGRESSO BRASILEIRO DE ECONOMIA E SOCIOLOGIA RURAL, 43, Ribeirão Preto, Anais..., SOBER: Ribeirão Preto, 2005.

MINAS GERAIS. Secretaria de Estado do Meio Ambiente e Desenvolvimento Sustentável (SEMAD). Gestão Ambiental no Século XXI (PE 17): termo de referência SAT/DIZON nº 001/05. Belo Horizonte: SEMAD/MG. Maio, 2005 .

MINISTÉRIO DO DESENVOLVIMENTO AGRÁRIO. Cooperação técnica para a formulação de uma política nacional de apoio ao desenvolvimento sustentável dos territórios rurais no Brasil. Documento: Referências para um Programa Territorial de Desenvolvimento Rural Sustentável. Cooperação MDA - CNDRS - NEAD - IICA. Série texto para discussão 4, 2003.

OLIVEIRA, I. S. D. A contribuição do zoneamento ecológico econômico na avaliação do impacto ambiental: bases e propostas metodológicas. 2004. 111p. Dissertação (Mestrado em Ciências da Engenharia Ambiental) - Universidade de São Paulo, São Carlos.

PEREIRA, J. R. Construção dos indicadores de potencialidade social. In: SCOLFORO, J. R. S.; OLIVEIRA, A. D.; CARVAlHO, L. M. T. (Ed.). Zoneamento ecológico-econômico do Estado de Minas Gerais: componente socioeconômico. Lavras: UFLA, 2008a. Cap. 1, p. 7-34.

Carta de potencialidade social. In: SCOLFORO, J. R. S.; OLIVEIRA, A. D.; CARVALHO, L. M. T. (Ed.). Zoneamento ecológico-econômico do Estado de Minas Gerais: componente socioeconômico. Lavras: UFLA, 2008 b. Cap. 7, p. 167-195.

PETTER, R. L.; PETTER, V. L.; QUADROS, F. A. S. Desenvolvimento territorial: uma análise espacial e sua relação com a ruralidade. Revista Brasileira de Agroecologia, Brasília, v.2, n.1, fev. 2007.

POCHMANN, M. et al. (Org.). Atlas da exclusão social, volume 4: a exclusão no mundo. São Paulo, Cortez, 2004. 229 p. 
PORTAL BRASIL. Programa de Aceleração do Crescimento: Relatório por Estado - MG: balanço de 4 anos 2010. 2010. Disponível: <http://www.brasil.gov.br/pac/relatorios/\%20estaduais/minas-gerais-1/minas-gerais-balanco-de-4anos>. Acesso em: 25 fev.2011.

SCHNEIDER, S. A abordagem territorial do desenvolvimento rural e as suas articulações externas. Sociologias, Porto Alegre, ano 6, n. 11, jan./jun. 2004, p. 88-125.

SCOLFORO, J. R. S.; OLIVEIRA, A. D.; CARVALHO, L. M. T. (Ed.). Zoneamento ecológico-econômico do Estado de Minas Gerais: componente socioeconômico. Lavras: UFLA, 2008. 195p.

SEN, A. Desenvolvimento como liberdade. São Paulo, Companhia das Letras, 2000. 409 p.

STEINBERGER, M.; ROMERO, M. B. Reflexões preliminares sobre as dimensões demográficas urbanas do zoneamento ecológico-econômico. In: ENCONTRO NACIONAL DA ABEP, 12, Caxambu, Anais..., ABEP: Caxambu, 2000.

TENÓRIO, F. G. Um espectro ronda o terceiro setor: o espectro do mercado. Ijuí, Editora da Unijuí, 2008.

VEIGA, J. E. Desenvolvimento territorial do Brasil: do entulho varguista ao zoneamento ecológico-econômico. Bahia Análise \& Dados, Salvador, v. 10, n. 4, março 2001, p. 193-206.

VIDAL, S. M. S. C.; Gestão território em Santos, SP, e sua interface portuária: apontamentos visando à definição de uma nova relação. In: ENCONTRO NACIONAL PÓS-GRAUDAÇÃO EM ADMINISTRAÇÃO, 28, Curitiba, Anais..., ENANPAD: Curitiba, 2004.

WESZ JUNIOR, V. J. Desenvolvimento territorial com agroindústrias familiares. In: CONGRESSO BRASILEIRO DE ECONOMIA E SOCIOLOGIA RURAL, 43, Ribeirão Preto, Anais..., SOBER: Ribeirão Preto, 2005. 